\title{
Vascular Complications of Parapharyngeal Abscesses
}

\author{
Michael AB Naafs* \\ Naafs International Health Consultancy, Europe
}

*Corresponding author: Michael AB Naafs, Internist-endocrinologist with a long clinical career in internal medicine and endocrinology, Naafs International Health Consultancy, Europe.

Received Date: October 08, 2018

Published Date: November 15, 2018

\begin{abstract}
A Dutch newspaper article reports serious complications, presumably due to internal carotid artery perforation, following poking a parapharyngeal abscess in a 15-year-old boy. The patient cannot walk and speak anymore and stays in a rehabilitation Centre. His parents are going in court with the hospital denying responsibility. An impressive picture concerning the impact on daily life of the patient and his family is presented. Diagnosis, treatment, management and vascular complications are briefly reviewed in general, showing multiple decision moments in this process. Open communication is a prerequisite in these matters. Backdoor reports and politics do not prevent calamities in the near future.
\end{abstract}

\section{Introduction}

The parapharyngeal space (PPS) is lateral to the superior pharyngeal constrictor and medial to the masseter muscle. This space connects to every other major fascial neck space and is divided into anterior and posterior compartments by the styloid process. The posterior compartment contains the carotid artery, internal jugular vein, and numerous nerves. Infections in the PPS usually originate in the tonsils or pharynx, although local spread from odontogenic sources and lymph nodes may occur [1].

Abscess swelling can compromise the airway. Posterior space abscess can erode in the carotid artery or cause septic thrombophlebitis of the internal jugular vein (Lemierre syndrome). Most patients have fever, sore throat and swelling in the neck down to the hyoid bone. Anterior space abscesses cause trismus and induration along the angle of the mandible, with medial bulging of the tonsil and lateral pharyngeal wall. Posterior space abscesses cause swelling that is more prominent in the posterior pharyngeal wall, trismus is minimal. Posterior abscesses may involve structures within the carotid sheath, possibly causing rigors, high fever, bacteremia, neurologic deficits, and massive hemorrhage caused by carotid artery rupture [1].

That vascular complications can have life-long sequelae is illustrated by a mother's story telling the case history of her 15-year-old boy to a Dutch newspaper [2]. For that reason, vascular complications and subsequent neurologic deficits in the treatment of parapharyngeal abscesses are discussed in this mini-review.

\section{Case History}

A 'simple' intervention on a throat abscess became Shiroma Joaquin [15] almost fatal. The doctor presumably pricked his carotid artery causing Shai to fall into a coma. He is still alive but cannot talk and walk now His parents are going to court [2].

It starts with a sore throat at the end of December with a lot of mucus, pain and fever in a few days and he can hardly speak. The next morning, he gets antibiotics and painkillers at the GP station of the local hospital. At night things got worse and he was referred to an on-duty ENT surgeon in a large teaching hospital The ENT surgeon poked the abscess and Shai began spitting thick blood and got a cardiac arrest After resuscitation Shai was transferred in coma to one of the ICU's of the University Hospital. On a scan it appears there is a probable iatrogenic hole in his carotid artery. Nine months later Shai cannot walk and speak and stays in a rehabilitation center. (see Shai and his mother and complete story in the newspaper article) [2].

No doubt this dramatic case with life-long sequelae raises several questions. However, as the case is still in court and some clinical data are lacking these questions cannot be answered, but a general review of diagnosis, treatment, management and 
complications of parapharyngeal abscesses seems nevertheless useful.

\section{Diagnosis}

As mentioned before, appearance of fever (64\%) and malaise are the first symptoms. Progression of infection leads to odynophagia (55\%), dysphagia, ptyalism. Decreased oral fluid intake leads to secondary dehydration. Physical examination reveals neck stiffness (65\%), oropharyngeal wall displacement (55\%), and tender lymphadenopathy (36\%). Lateral cervical swelling (55\%) indicates large volume pus in the PPS [3]. In addition to fiberoptic endoscopy, a computed tomographic (CT) scan is the radiologic test of choice. It provides details of the size, location of the abscess and position relative to the large vessels. Relationship of the abscess cavity, particularly the retropharyngeal is very well delineated on CT scan (spread to retropharyngeal space has life-threatening risk of mediastinitis). Differentiation between cellulitis and small abscesses is poor with specificity of $45 \%$. These details aid in deciding the mode of treatment [4].

\section{Medical management}

In treatment of deep neck infections, intensive antibiotic therapy and surgical drainage are complementary to each other. These patents need high dependency intensive care. Dehydration needs immediate correction. Aggressive intravenous antibiotics coverage is very essential. In small volume of abscesses without systemic toxicity, only antibiotic therapy can be attempted. If general condition decorates or there is failure of regression of abscess cavity, surgical intervention is advised [5].

For first 72 hours antibiotic therapy must be empirical because most 'pure' parapharyngeal abscesses are not easily accessible to aspiration and commensal organisms complicate the issue. The first-line intravenous antibiotic of choice is amoxicillin with clavulanic acid $(150 \mathrm{mg} / \mathrm{kg} /$ day $)$ because most of deep neck abscesses contain beta-lactamase producing organisms. Anaerobic coverage is provided with intravenous metronidazole $(0,5 \mathrm{gm})$ every 6 hourly.

\section{Management of airway}

Clinical examination is essential to look for decreased interdental gap, narrowing of oropharyngeal isthmus. So, oral intubation can be quite challenging. In case of pus pointing on oropharyngeal mucosa, direct laryngoscopy has the risk of rupture of the abscess with subsequent aspiration. In such cases awake fiberoptic intubation is a good option for assuring the difficult airway and avoiding a tracheostomy [6,7]. In difficult cases, tracheostomy under local anesthesia is a safe and reliable method to secure and stabilize the airway..

\section{Surgical approach}

Surgical approaches can be classified into intraoral and extraoral approaches.

\section{Intraoral approach}

Several pediatric studies are favoring the intraoral approach. This becomes paradoxical when one is dealing with locations that are medial to the great vessels, especially in children. Intraoral drainage of parapharyngeal abscesses can be performed indistinctly by puncture drainage or incision drainage $[8,9]$. This procedure can be performed under topical anesthesia in the case of accessible abscesses and with patients who are capable of sufficient collaboration. General anesthesia and orotracheal intubation is needed in small children. Trendelenburg position is adopted to prevent aspiration of pisiform incision drainage, a longitudinal incision is made on the pharyngeal wall. If required intraoral surgical treatment can be repeated after 12-24 hours. Intraoral drainage has the advantage of less morbidity, shorter hospital stays and lower hospital costs and is less aggressive in comparison with external drainage.

Intraoral drainage is contraindicated for abscesses that are lateral to the large vessels and complicated abscess that involve several compartments. Surgical drainage carries its own inherent risks and potential complications. To minimize these complications image-guided aspiration has evolved. In selected cases percutaneous aspiration of abscess cavity under ultrasound or CT guidance has evolved as an alternative to conventional surgery. Ultrasound is widely accepted due to its wide availability.

\section{External approach}

The external approach to the PPS is performed through a horizontal incision in the cervical crease. Depending on the extent of the abscess, modified apron incision and hockey stick incision are described [10]. Types of drain to be used after evacuation of abscess depends on size of abscess cavity and surgeon's preference.

\section{Vascular complications}

Lemierre's syndrome is characterized by septicemia, internal jugular vein thrombophlebitis and septic emboli that arise secondary to acute oropharyngeal infections. Surgical drainage within antibiotic therapy is the primary modality of treatment. Antibiotics are usually administered for 3-6 weeks. Metastatic emboli are known to occur. So, anticoagulation is advised to prevent spread of infection and catastrophe of septic emboli at circulatory end points. Medical treatment with antibiotics and anticoagulants are continued till leukocytosis and ESR returns to baseline levels. Nutritional support needs special attention. Nasogastric tube feeding is preferred [11.12].

Although traumatic carotid injuries occur rarely their mortality rates have been reported from $17 \%$ to $40 \%$ and significant neurologic complications ranging from $40 \%$ to $80 \%$. Diagnosis is made by CT-angiography. Perforation or rupture require surgery or endovascular stenting procedures [13]. Children with parapharyngeal lateral retropharyngeal abscesses $(n=45)$ all had narrowing in the adjacent carotid lumen to some degree in a study by Derinkuya et al. [14].

The two main vascular complications reported in the literature are extrinsic carotid artery stenosis due to compression by the abscess and pseudoaneurysm [14,15]. Internal carotid artery aneurysms can mimic peritonsillar abscess and incision drainage can be fatal [16]. Infectious arteritis of the internal carotid artery with pending rupture is rare [17]. 


\section{Conclusion}

It is obvious there are a lot of decision moments in the treatment and management of 'simple' deep neck abscesses. For example, was acute drainage in the middle of the night in a treatment room necessary? Was the choice for intraoral drainage the right one? Would admission at the ICU with intubation possibilities and subsequent ultrasound or CT scan the other day. had another outcome, e.g. external drainage? Although complications are rare, they can be very serious as the case of 15-year-old Shai shows. Patient, family members, ENT surgeons, lawyers, all will have a different look at these decision moments. It is clear every procedure has its inherent risks and complications. Open communication about these matters is a prerequisite. Backroom reports and politics do not prevent these calamities in the near future.

\section{Acknowledgement}

None.

\section{Conflict of Interest}

None.

\section{References}

1. Sasaki CT (2018) Parapharynheal Abscess. MSD Manual.Professionl Version.

2. Van der Mee T, Shai (15) can no longer talk and walk after a doctor's surgery he runs throat abscess. 2018;Sept 26.;Google Translate. https:// www.tubantia.nl/binnenland/shai-kan-niet-meer-praten-en- lopen- naingreep-arts-bij-keelabces-a297a274/

3. Meher R, Agarwal S, Singh I (2006) Tuberculous retropharyngeal abscess in an HIV patient. Hong Kong Med J 12(6): 483-485.

4. Kessler A. Accuracy of ultrasonography versus computed tomography scan in detecting parapharyngeal abscess in children. Pediatr.Emerg. Care 28(8): 780-782.

5. Booth T, McClay JE, Murray AD (2003) Intravenous antibiotic therapy for deep neck abscesses defined by computed tomography. Arch Otolaryngol Head Neck Surg 129(11): 1207-1212.
6. Sethi DS, Stanley RE (1994) Deep Neck Abscesses. J Laryngol Otol 108(2): 138-143.

7. Raval CB, Khan S (2012) Airway management in submandibular abscess patient with awake fiberoptic intubation-a case report. Middle East J Anaesthesiol 21(4): 647-651.

8. Marques PM, Spratley JE, Leal LM, Cardoso E, Santos M (2009) Parapharyngeal abscesses in children-five year retrospective study. Braz J Otolaryngol 75(6): 826-830.

9. Wong DK, Brown C, Mills N, Spielmann P, Neeff M (2012) To drain or not to drain-management of pediatric deep neck abscesses. A case-control study. Int J Pediatr Otorhinolaryngol 76(12): 1810-1813.

10. Baily BJ,Calhoun KH,Friedman N (2001) Atlas of Head and Neck Surgery. Otolaryngology Lippincott Williams\&Wilkins 166.

11. Lashminarayama PH, Matthew E Woodske (2010) A unique case of Lemierre syndrome associated with thrombophlebitis in an adult and the role of anticoagulation. Case Rep Med: 982494.

12. Alaani A, Griffiths H, Minhas SS, Olliff J, Lee AB (2005) Parapharyngeal abscess:Diagnosis,complications and management $\mathrm{n}$ adults. Eur Arch Otorhinolaryngol 262(4): 345-350.

13. Lee C, Park JS, Hwang KW, Seung-Whan Lee, Seong-Wook Park, et al. (2011) Procedure-induced Acute Common Carotid Artery Perforation Presenting With Airway Obstruction and Successsful Treatment by Endovascular Stent Graft. Korean Circ J 41(7): 405-408.

14. Derinkuyu BE, Boyanaga O, Polat M, Damar Ç, Tapısız Aktaş A, et al. (2017) Association between deep neck space abscesses and internal carotid artery narrowing in pediatric patients. Turk J Med Sci 47(6): 1842-1847.

15. Elliot M, Yong S, Beckenham T (2006) Carotid artery occlusion in association with a retropharyngeal abscess. Int J Pediatr Otorhinolaryngol 70(2): 359-363.

16. Brzost J, Cyran AM, Waniewska M, Szczepanski MJ (2015) Internal Carotid Artery Aneurysm Mimicking Peritonsillar Abscess. Case Rep Otolaryngol 389298.

17. Lisan Q, Tran H, Veriland B, Herman P (2016) Infectious arteriitis of the internal carotid artery complicating retropharyngeal abscess. Eur Ann Otorhinolaryngol Head Neck Surg. 133(1): 55-57. 